\title{
The influence of global discourse on lexical ambiguity resolution
}

\author{
HOANG VU, GEORGE KELLAS, KIMBERLY METCALF, and RUTH HERMAN \\ University of Kansas, Lawrence, Kansas
}

\begin{abstract}
The influence of global discourse on the resolution of lexical ambiguity was examined in a series of naming experiments. Two-sentence passages were constructed to bias either the dominant or the subordinate meaning of a homonym that was embedded in a locally ambiguous sentence. The results provided evidence for the immediate ( 0 -msec interstimulus interval) resolution of lexical ambiguity and were subsequently replicated in Experiment 2, in which an 80-msec stimulus onset asynchrony exposure duration was employed for the homonyms. Strong dominant and subordinate biased discourse contexts activated only the contextually appropriate sense of a homonym. In Experiment 3, each sentence of the discourse was presented in isolation. The pattern of activation obtained in Experiments 1 and 2 was found to be contingent on the integration of the two sentences to construct an overall global discourse representation of the text. The results support a context-sensitive model of lexical ambiguity resolution.
\end{abstract}

Over the past two decades, lexical ambiguity research has sustained a theoretical dichotomy in which the processing of an ambiguous word (e.g., a homonym) is either influenced by context or impervious to it. The bulk of the research on whether context can immediately influence lexical ambiguity resolution has produced mixed results. Early studies supported the principles of modularity (see Fodor, 1983; Forster, 1979), in which the process of word meaning activation is encapsulated and independent of higher level influences of syntax and semantics (e.g., Onifer \& Swinney, 1981; Seidenberg, Tanenhaus, Leiman, \& Bienkowski, 1982; Swinney, 1979). For example, Swinney presented passages aurally, each of which contained an ambiguous word, and found that lexical decision times for both contextually appropriate and inappropriate target words were faster than those for unrelated words. Seidenberg et al. (1982) also employed the crossmodal priming paradigm, but used a naming task as an index of priming, and found that naming latencies for target words that were related to the dominant and subordinate meanings of words with noun/verb ambiguities were faster than those for unrelated target words.

More recent research has presented a challenge for the modular view of ambiguity resolution. Several studies have supported an interactive activation framework (see Marslen-Wilson \& Tyler, 1987; McClelland, 1987), in which context can immediately influence meaning activation in such a way that only the contextually appropriate meaning of an ambiguous word is activated (e.g., Paul, Kellas, Martin, \& Clark, 1992; Simpson, 1981; Simpson \& Krueger, 1991; Van Petten \& Kutas, 1987; Vu, Kel-

We thank Robert Lorch and two anonymous reviewers for their contribution to the final manuscript. Correspondence should be addressed to G. Kellas, Department of Psychology, University of Kansas, Lawrence, KS 66045 (e-mail: gkellas@ukans.edu). las, \& Paul, 1998). For example, Vu et al. demonstrated that target words that were rated to be strongly related to one meaning (dominant or subordinate) of an ambiguous word in context were primed in comparison with unrelated target words or contextually inappropriate targets. Even studies that do not support a fully interactive activation framework have provided evidence for an immediate influence of biasing context on the processing of an ambiguous word (e.g., Duffy, Morris, \& Rayner, 1988; Tabossi, 1988; Tabossi, Colombo, \& Job, 1987; Tabossi \& Zardon, 1993).

The consensus from earlier studies in which crossmodal priming was used to examine lexical ambiguity resolution and the time course of activation (e.g., Seidenberg et al., 1982; Swinney, 1979; Tanenhaus, Leiman, \& Seidenberg, 1979) is that selection of the contextually appropriate meaning from a pool of activated meanings occurs within $200 \mathrm{msec}$ from the offset of an ambiguous word. Within this time period, all alternative meanings are activated, but if the priming methodology employed fails to capture this critical time frame, the results will suggest selective activation. Conflicting evidence has been obtained with the use of cross-modal techniques as an index of meaning activation, however. For example, Seidenberg et al. found evidence for multiple activation for ambiguous words with noun/verb alternative meanings. In contrast, for ambiguous words of the noun/noun type, Seidenberg et al. (Experiments 2 and 4 ) found evidence for selective activation. ${ }^{1}$ Similarly, Tabossi (e.g., Tabossi, 1988; Tabossi et al., 1987) used a cross-modal task and reported results showing selective activation of target words that were related to the dominant meaning of an ambiguous word when the targets immediately followed a dominant biasing context. More important, there is mounting evidence that selective acti vation can be immediately obtained (i.e., a 0 -msec interstimulus interval 
[ISI]) using several different measures, including naming (e.g., Simpson, 1981; Simpson \& Krueger, 1991; Vu et al., 1998), modified Stroop (Paul et al., 1992), event-related potentials (e.g., Van Petten \& Kutas, 1987), and crossmodal priming (e.g., Tabossi, 1988; Tabossi et al., 1987).

The convergence of evidence in support of contextual influences on meaning activation has led to a consideration of additional factors contributing to the process of lexical ambiguity resolution. Results from a number of studies have shown that the pattern of meaning activation obtained is not independent of context, but instead is contingent (in part) on a complex relationship between biasing context and meaning frequency (e.g., Duffy et al., 1988), as well as strength of context (e.g., Simpson, 1981; Simpson \& Krueger, 1991; Vu et al., 1998). The relationship among these variables has led to the development of two more recent models of lexical ambiguity resolution.

\section{Reordered Access Model}

According to the reordered access model (see, e.g., Dopkins, Morris, \& Rayner, 1992; Duffy et al., 1988; Pacht \& Rayner, 1993; Rayner, Pacht, \& Duffy, 1994), the meanings of an ambiguous word are exhaustively accessed. ${ }^{2}$ If a homonym is balanced (i.e., has equally used meanings), its meanings are simultaneously (equally) accessed; and if the ambiguous word is polarized (i.e., has one frequently used meaning), the meanings are accessed in order of frequency, with the most frequent (dominant) meaning being accessed first, followed by access of the least frequent (subordinate) meaning(s). Prior context can reorder the availability of a specific meaning by boosting its activation level, provided that the context biases that meaning. An important finding that has been consistently demonstrated in research supporting the reordered access model is that when a polarized ambiguous word is preceded by a subordinate biased context, reading time is longer for an ambiguous word than for an unambiguous control word. The longer processing time is assumed to reflect the simultaneous and equal access of the dominant (due to meaning frequency) and subordinate (due to context) meanings. However, regardless of the specifications of context and meaning frequency, the reordered access model includes the fundamental premise that all meanings of an ambiguous word are initially accessed in all contexts.

\section{Context-Sensitive Model}

According to the context-sensitive model of ambiguity resolution (see Paul et al., 1992; Vu et al., 1998), meaning activation is sensitive to context, and a continuum of graded meaning activation is possible, depending on the overall strength of context (i.e., the degree of constraint that context places on an ambiguous word). According to this proposal, multiple sources of constraint (e.g., lexical, syntactic, semantic, pragmatic) combine during text processing to produce a representation of the context (see Kawamoto, 1993; Kellas, Paul, Martin, \&
Simpson, 1991; McClelland, 1987; Paul et al., 1992; Tabossi et al., 1987; Taraban \& McClelland, 1988; Vu et al., 1998). Each source of constraint is instrumental insofar as it contributes to the evolving discourse representation. Individual constraints may vary in their influence, but no single constraint will dominate the process of word meaning activation (cf. McClelland, 1987; McClelland, St. John, \& Taraban, 1989). Instead, the critical parameter for computation of activation is the overall strength of the biasing context, as produced by the convergence of the multiple constraints. When contextual bias is strong, computation of the contextually appropriate meaning will immediately occur, and when the context is weak, computation of multiple meanings is possible. Empirical support for the context-sensitive model comes from the research of Simpson (1981), Simpson and Krueger (1991), and Vu et al. (1998). In these investigations, it was demonstrated that sentences empirically rated to be strong activated only the contextually appropriate meaning of a homonym. However, sentences rated as being ambiguous (supporting both meanings) activated both senses of the ambiguity.

In sum, both models outlined above incorporate the conjoint effects of contextual bias and meaning frequency but differ on the importance of each variable. For the reordered access model, meaning frequency has a strong influence on word meaning activation. Context can reorder the availability of an activated meaning, yet all meanings are exhaustively activated in all contexts. In contrast, it is the overall strength of context that is critical for the context-sensitive model. Activation of word meanings can be selective or exhaustive, depending on the strength of the biasing context. Martin, Vu, Kellas, and Metcalf (1999) examined contextual strength and meaning frequency in order to determine the relative contribution of each variable to the process of ambiguity resolution. The results showed that when the contexts employed were weakly biased, meaning frequency was an important factor and multiple activation of the meanings of an ambiguous word was obtained, but when the context was strongly biased, selective activation of the appropriate meaning of the ambiguous word was found even for the most polarized ambiguous words. Martin et al. found that increasing asymmetries between the dominant and subordinate meaning frequencies led to increasingly longer processing time of an ambiguous word in weakly biased contexts (i.e., graded effects). In contrast, when the context was strongly biased, this relationship was not observed, and processing of the ambiguous word was not affected by meaning frequency.

Another issue in the study of word meaning activation is the locus of context effects. The debate involves whether the effect of context is limited to the local context within which the critical word is embedded or whether a more global discourse context can also affect lexical activation. Kintsch and Mross (1985) provided evidence that global discourse does not contribute to lexical activation, 
but instead is necessary for text integration. However, Hess, Foss, and Carroll (1996) demonstrated a marked influence of global context on the processing of unambiguous words. It was found that processing of a critical word in its local context was facilitated only when the word was consistent with the global context. When the critical word was consistent in its local context but not the overall global context, processing was delayed. With respect to lexical ambiguity resolution, it has been suggested that prior context can influence processing of an ambiguous word only at the local level via intralexical priming. Global information cannot affect initial processing and is used only during text integration (cf. Binder \& Morris, 1995; Rayner et al., 1994).

In contrast, a more interactive approach to lexical processing assumes that the language processor can capitalize on global discourse information as well as local information. As a constraint-based model, the context-sensitive model presumes that constraints on lexical processing can arise from several sources, whether from the local context (e.g., syntax, semantics) or from a more global discourse context (e.g., pragmatics). Incremental (wordby-word) processing of a context produces a dynamic representation of the text that is continuously updated. The evolving representation, in turn, modulates (constrains) interpretation of subsequent lexical input. This interactive process of updating and modulation terminates with the last lexical input, producing a final representation. The representation can be strongly or weakly biased, depending on the constraints of the context (as well as general world knowledge). Thus, the context-sensitive model assumes an influence of context at all levels, from an isolated sentence to larger segments of discourse.

Lexical ambiguity resolution in discourse contexts has been examined by Swinney (1979), Rayner et al. (1994), and Binder and Morris (1995), but unfortunately, it is difficult to clearly determine the extent to which global context interacted with lexical ambiguity in these studies. The seminal work of Swinney (1979) examined ambiguity resolution in short passages (Experiment 1). However, Swinney's results cannot be attributed to either local or global contexts specifically, because the stimuli (twosentence passages) were constructed to restrict biasing information to the last sentence of the passage in which the ambiguous word was encountered. The first sentence of each passage was neutral regarding the alternate meanings. Consequently, the results cannot be clearly attributed to the influence of global discourse on meaning activation as opposed to a local influence. In fact, in Experiment 2, Swinney used only the strongly biased terminal sentences of the passages as primes (single-sentence stimuli) and obtained the same outcome as with the short passages, suggesting that the results were, in fact, due to the local influence of the biasing sentences. More recent research by Rayner et al. (1994) and Binder and Morris manipulated global discourse context to bias the subordinate meaning of ambiguous words. However, in both studies, the local context preceding an ambiguous word contained information that also constrained the subordinate meaning. Since both global and local context biased the subordinate meaning of an ambiguous word, it cannot be determined whether the constraint placed on meaning activation was due to a global or a local influence (or both).

The purpose of the present research was to examine further whether or not more global discourse-level information can affect the processing of a locally ambiguous word. The difference in this research is that biasing information was restricted to the global discourse while the local context that included an ambiguous word did not contain disambiguating information. ${ }^{3}$ On the basis of previous research demonstrating that strongly biased sentence contexts can produce immediate selective activation (Simpson, 1981; Simpson \& Krueger, 1991; Vu et al., 1998), we predicted that selective activation could also be obtained with the use of strongly biased discourse contexts. To that extent, we employed discourse contexts that were empirically determined to be strongly biased toward one sense (dominant or subordinate) of an ambiguous word. Because we wanted to demonstrate that the influence of context was due to global discourse information and not due to the local context, it was imperative that the local contexts employed did not provide information to disambiguate the embedded homonym. Instead, we wanted to use local contexts that were ambiguous - that is, equally supportive of both meanings of an ambiguous word. For this requirement, the ambiguous sentences from $\mathrm{Vu}$ et al. (1998) were employed. The ambiguous nature of these sentences was empirically determined by participants' ratings and in a series of naming experiments which showed that both meanings of an ambiguous word were activated following these sentences.

Short passages were constructed by preceding each ambiguous sentence from Vu et al. (1998) with a biasing sentence. The first sentence of each passage described a single agent (subject noun) engaged in some activity. The second, ambiguous sentence began with a pronoun ( $\mathrm{s} / \mathrm{he}$ ) and terminated in an ambiguous word (e.g., "He received the pass"). The pronoun of the second sentence unambiguously referred to its antecedent (the agent) in the first sentence. The information contained in the first sentence signified which sense of the upcoming ambiguity was appropriate but only insofar as the two sentences were integrated and an overall global discourse representation was constructed. If we obtained immediate selective activation in the presence of ambiguous local contexts, we would be able to conclude that the influence of context must be at the discourse level, because the local context contained no disambiguating information.

In Experiment 1, we investigated the influence of strongly biased global discourse on the resolution of ambiguous words by examining naming latencies to target words associated with the alternative neanings of the homonyms. Experiment 2 was designed to replicate the results of Experiment 1, but with the ambiguous word presented for only 80 -msec stimulus onset asynchrony (SOA) 
to further ensure the immediacy of meaning activation. In Experiment 3, the individual sentences constituting the passages were presented in isolation to verify that the pattern of activation obtained in Experiments 1 and 2 was indeed due to a global representation, and not to the individual sentences per se. In addition, naming latencies to target words following the ambiguous sentences were expected to show multiple activation, thus replicating the research of Vu et al. (1998). The results of the research were subsequently evaluated in light of the context-sensitive model and the reordered access model of lexical ambiguity resolution.

\section{EXPERIMENT 1}

Naming latencies for target words were examined to determine whether higher level discourse information can constrain meaning activation of ambiguous words embedded in ambiguous local contexts. If prior discourse information does not influence ambiguity resolution, multiple activation is predicted to occur because of the ambiguous local context, regardless of whether the global discourse is biased toward a dominant or a subordinate interpretation. Such an outcome would be compatible with the thesis of reordered access, because the model assumes an influence of local context but not global context (Rayner et al., 1994). In contrast, the contextsensitive model predicts that the two sentences, when integrated into a global representation rated to be strongly biased, should provide immediate activation of only the contextually appropriate meaning for both dominant and subordinate contexts.

\section{Method}

Participants. Forty-eight undergraduate volunteers from introductory psychology courses participated in the naming experiment for class credit. All were native English speakers with normal or corrected-to-normal vision. An additional 100 participants provided normative data.

Stimuli. One hundred and sixty ambiguous sentences containing 160 different sentence-final homonyms from Vu et al. (1998) were selected. The sentences were all of the form pronoun, transitive verb, and direct object (e.g., He received the pass). Sentence ambiguity was established by Vu et al. with off-line ratings of sentence bias and in a series of naming experiments in which multiple activation was found. The homonyms were selected from the association norms of Nelson, McEvoy, Walling, and Wheeler (1980) and Twilley, Dixon, Taylor, and Clark (1994). Short passages were constructed by preceding the ambiguous sentences with sentences containing information that, when combined with the second sentence, could be used to bias the meaning of a passage-final ambiguous word. The passages were constructed to convey a specific situation without any topic shift. The subject noun in the first sentence represented the only animate entity introduced and served as the grammatical subject (and agent) receiving focus (cf. Sanford \& Garrod, 1981), and the pronoun in the second sentence unambiguously identified its antecedent in terms of number and gender. Additionally, care was taken to ensure that no words in a passage were direct lexical associates of the terminal ambiguous word or the target words to be named. Two associates representing the dominant and subordinate meanings of the homonyms were selected as target words. These target words were selected from Nelson et al. (1980) and Twilley et al.
(1994) and were identical to those used by Vu et al. (1998). All homonyms used were of the noun/noun form.

Two passages were constructed for each homonym, one representing a dominant, and the other a subordinate, context. This made a total of 320 experimental passages. The particular bias of each passage was initially agreed upon by a panel of six judges. The passages were subsequently divided into two sets of 160 . Within each set, the order of the 160 passages was reversed for presentation to one half of the participants to avoid potential order effects. All four subsets were presented to four groups of 20 participants each. Participants rated the degree to which each passage was biased toward the associatively related target words on a 7-point scale (where 1 represented a strong bias toward the dominant meaning and 7 represented a strong bias toward the subordinate meaning). Strict criteria were used in selecting the experimental stimuli from participants' ratings. For each homonym, strongly biased dominant passages had to be rated between 1.00 and $2.25(M=1.64, S D=$ $1.11)$, and strongly biased subordinate passages between 5.75 and $7.00(M=6.34, S D=1.14)$. On the basis of the criteria above, 192 strongly biased primes (using 96 homonyms) were selected for study. The constructed passages did not render the passage-final ambiguous words or subsequent targets predictable, according to cloze probabilities examined for 20 participants. For dominant biased passage frames (i.e., passages sans final word), the cloze probabilities were .06 for the homonyms and .04 for the target words. For the subordinate biased passage frames, the cloze probabilities were .04 and .03 for the homonyms and target words, respectively. The low probabilities indicated that the passage frames were not predictive. The range of meaning frequency for the homonym corpus was .51-1.00, with a mean of .79 for the dominant sense. The procedure for defining polarity was adopted from Rayner and Frazier (1989); probability values were based only on the two alternatives used in the study. Responses other than the two alternatives were eliminated, so that probability computation summed to 1.00 in all cases.

Each prime passage (dominant or subordinate) was paired with two related target words (dominant, subordinate). Unrelated conditions were created by randomly repairing related primes and targets, with no prime or target being repeated within participants. In order for each prime and target to appear only once per participant with each participant exposed to all conditions, eight stimulus lists were constructed. Each list consisted of an equal number of eight possible prime-target conditions, with 12 homonyms per condition, resulting in a total of 96 experimental trials per list. In addition, 24 passages with unique homonyms were created from the remaining 160 rated passages for reading rate calibration (discussed below), and another 36 served as practice trials. These 60 passages were representative of the experimental conditions and were identical for all participants. Table 1 contains an example of the stimuli used for each of the conditions. The full stimulus set is presented in the Appendix.

Targets were approximately equated across conditions on number of letters (dominant, $M=5.03, S D=1.45$; subordinate, $M=$

\section{Table 1}

Examples of Prime and Target Stimuli Across All Conditions in Experiments 1 and 2

\begin{tabular}{llll}
\hline \multirow{2}{*}{ Bias } & \multicolumn{1}{c}{ Passage Prime } & \multicolumn{2}{c}{ Targets } \\
\cline { 3 - 4 } Dominant & $\begin{array}{l}\text { The rookie raised his hands. } \\
\text { He received the pass. }\end{array}$ & Unrelated \\
Subordinate & $\begin{array}{l}\text { The caller won the contest. } \\
\text { He received the pass. }\end{array}$ & TICKET & ASSAULT \\
Dominant & $\begin{array}{l}\text { The technician was incompetent. } \\
\text { He overlooked the battery. }\end{array}$ & CAR & FOOTBALL \\
Subordinate & $\begin{array}{l}\text { The judge was lenient. } \\
\text { He overlooked the battery. }\end{array}$ & ASSAULT & TICKET \\
\hline
\end{tabular}


5.46, $S D=1.95 ; p=.09$ ), syllables (dominant, $M=1.5, S D=$ 0.7 ; subordinate, $M=1.6, S D=0.9 ; p>.38$ ), bigram frequency (dominant, $M=5,330.7, S D=3,740.9$; subordinate, $M=5,210.1$, $S D=3,749.7 ; p>.80$; from Massaro, Taylor, Venezky, Jastrzembski, \& Lucas, 1980), and frequency of occurrence in the English language (dominant, $M=113.0, S D=264.3$; subordinate, $M=$ $85.9, S D=147.0 ; p>.33$; from Kučera \& Francis, 1967).

Apparatus. The stimuli were presented on an IBM-compatible 486 personal computer with an NEC Multisync-Plus color monitor. A Shure microphone (Model 515SB), attached to a Grason-Stadler E7300A-1 voice-operated relay (VOR), was interfaced with the computer to signal verbal responses. Stimulus presentation was synchronized to the refresh rate of the monitor, and response times were measured to the nearest millisecond from the onset of the target to the triggering of the VOR by a vocal response.

Procedure. All participants were tested individually in a dimly lit room and were seated approximately $60 \mathrm{~cm}$ from the computer monitor so that targets subtended an average visual angle of about $1.6^{\circ}$ horizontally and $0.5^{\circ}$ vertically.

The procedure for stimulus presentation resembled a moving window format (cf. Just, Carpenter, \& Woolley, 1982) in which words constituting a context were presented one at a time across the computer screen, but with the difference that the words remained visible until the final word was displayed. This unfolding procedure has been successfully employed in previous studies of on-line language processing, including Dell, McKoon, and Ratcliff(1983) and Greene, McKoon, and Ratcliff (1992) for pronoun resolution, and Paul et al. (1992) for lexical ambiguity resolution. We modified the procedure to include the option to calibrate the presentation rate so that it was tailored to each individual participant's reading speed. This modification enabled a more precise estimate of the ISI between presentation of the prime and the subsequent target word for each participant. Using a predetermined rate of presentation for all participants would have created long ISIs for fast readers, and slow readers might not have had an opportunity to finish reading the terminal homonym before the target word was presented. Thus, a standard presentation rate might do more to contaminate and compromise the results.

The participants were instructed to read the presented passage silently at their normal reading speeds and to read for comprehension. The set of 24 calibration passages was presented one word at a time at an initial rate of $198 \mathrm{msec}$ per word. The first sentence of each passage began at the left side and vertical center of the computer screen. The second sentence was presented directly beneath the first. Prime passages were displayed in lowercase letters (with the exception of the first letter of the first word in both sentences, which were capitalized); targets were presented in uppercase letters, so that they would be visually distinguishable from the passages. For each calibration trial, a series of word-length lines, each separated by a single space, was presented for $1 \mathrm{sec}$. The lines served as a warning signal and as location and length cues for the words constituting the upcoming passage. After each calibration trial, the participants answered a $w h-$ question about the passage that had just been presented. The participants were then asked whether the display rate was "too fast, too slow, or about right." The experimenter then adjusted the exposure rate (in increments or decrements of about $17 \mathrm{msec}$ ) in accordance with the participants' self-reports. After the calibration trials, the display rate was fixed for the remainder of the experiment.

Next, the participants were given instructions for the naming task. The procedures for the naming task were the same as those for the calibration trials, except that immediately following the passagefinal word ( 0 -msec ISI), the passage was removed and a target word was displayed six character spaces to the right of where the last word of the last sentence of the passage had previously ended. The participants were instructed to name the target aloud as quickly and as accurately as possible. To safeguard against the strategy of not reading the passages for comprehension, the participants were asked to answer wh- comprehension questions on a random $20 \%$ of the trials.

Naming responses were monitored for accuracy and legality. Response errors included incomplete responses, mispronunciations, extraneous noises loud enough to trigger the VOR, and artificial delays resulting from responses that initially failed to trigger the VOR. All trials were separated by a 2,500-msec intertrial interval, and responses to the first 36 naming trials constituted practice and were not examined.

\section{Results}

Two participants were replaced because of excessive naming errors $(>10 \%)$. The participants' mean calibrated reading speed was $266 \mathrm{msec}$ per word $(S D=42 \mathrm{msec}$ ). Response errors constituted only $4.7 \%$ of the data, and comprehension accuracy was $80.4 \%$.

Mean correct naming latencies were subjected to a discourse bias (dominant bias, subordinate bias) $\times$ target dominance (dominant, subordinate) $\times$ target relatedness (related, unrelated) analysis of variance for repeated measures, with both participants $\left(F_{1}\right)$ and items $\left(F_{2}\right)$ as random factors. All the effects to be reported here were significant at $p<.05$ unless otherwise indicated. Mean naming latencies, percent errors, and magnitude of priming are shown in Table 2.

Table 2 indicates that naming latencies for contextually appropriate target words following both dominant and subordinate passages were facilitated relative to latencies in unrelated conditions, whereas latencies for inappropriate targets were not. This description is supported by the following statistical outcomes.

Analyses revealed reliable effects of target dominance and target relatedness, and an interaction of discourse bias $\times$ target dominance. However, these effects were qualified by the interaction of discourse bias $\times$ target dominance $\times$ target relatedness $\left[F_{1}(1,47)=16.41, M S_{\mathrm{e}}=\right.$ $\left.813.59 ; F_{2}(1,95)=8.13, M S_{\mathrm{e}}=4,113.70\right]$. The threeway interaction was examined further by evaluating target dominance $\times$ target relatedness for each discourse bias separately. For the dominant bias condition, there was an interaction of target dominance $\times$ target related-

Table 2

Mean Naming Latencies (in Milliseconds), Percent Errors, and Magnitude of Priming for Experiments 1 and 2

\begin{tabular}{|c|c|c|c|c|c|c|c|c|}
\hline \multirow[b]{4}{*}{ Target } & \multicolumn{8}{|c|}{ Passage Prime } \\
\hline & \multicolumn{4}{|c|}{ Dominant } & \multicolumn{4}{|c|}{ Subordinate } \\
\hline & \multicolumn{2}{|c|}{$\begin{array}{c}\text { Dominant } \\
\text { Target }\end{array}$} & \multicolumn{2}{|c|}{$\begin{array}{c}\text { Subordinate } \\
\text { Target }\end{array}$} & \multicolumn{2}{|c|}{$\begin{array}{c}\text { Dominant } \\
\text { Target }\end{array}$} & \multicolumn{2}{|c|}{$\begin{array}{c}\text { Subordinate } \\
\text { Target }\end{array}$} \\
\hline & $M$ & $\% \mathrm{E}$ & $M$ & $\% \mathrm{E}$ & $M$ & $\% \mathrm{E}$ & $M$ & $\% \mathrm{E}$ \\
\hline \multicolumn{9}{|c|}{ Experiment 1} \\
\hline Unrelated & 667 & 4.5 & 674 & 4.2 & 671 & 6.1 & 680 & 5.9 \\
\hline Related & 639 & 2.1 & 670 & 5.6 & 666 & 3.6 & 651 & 5.4 \\
\hline Priming & $28^{*}$ & 4 & 5 & $29 *$ & & & & \\
\hline \multicolumn{9}{|c|}{ Experiment 2} \\
\hline Unrelated & 780 & 4.5 & 781 & 6.1 & 776 & 2.8 & 786 & 3.6 \\
\hline Related & 752 & 1.7 & 774 & 5.6 & 775 & 3.1 & 761 & 3.3 \\
\hline Priming & \multicolumn{2}{|c|}{$28^{*}$} & \multicolumn{2}{|c|}{7} & \multicolumn{2}{|c|}{1} & \multicolumn{2}{|c|}{$25^{*}$} \\
\hline
\end{tabular}


ness $\left[F_{1}(1,47)=7.88, M S_{\mathrm{e}}=824.59 ; F_{2}(1,95)=3.26\right.$, $\left.M S_{\mathrm{e}}=6,087.51 ; p=.07\right]$. As Table 2 indicates, following dominantly biased passages, responses to dominant targets were facilitated relative to responses to unrelated targets $[t(47)=5.06]$. On the other hand, responses to subordinate targets were not facilitated relative to responses to unrelated targets $[t(47)=.80, p>.40]$. Naming latencies for the subordinate bias condition showed the opposite pattern. Again, there was an interaction of target dominance $\times$ target relatedness $\left[F_{1}(1,47)=12.00\right.$, $M S_{\mathrm{e}}=570.78 ; F_{2}(1,95)=2.97, M S_{\mathrm{e}}=4,668.29 ; p=$ $.09]$. Following subordinately biased passages, responses to subordinate targets were facilitated relative to responses to unrelated targets $[t(47)=6.55]$. Alternatively, responses to dominant targets were not facilitated relative to responses to unrelated targets $[t(47)=.90, p>.35]$.

Because a large number of cells had zeroes for entries, a formal analysis of the error rates was not conducted. No evidence of a speed-accuracy tradeoff was found, however, as was indicated by the Pearson's correlation coefficient obtained for the comparison of naming latencies and error rates $(r=+.65)$.

\section{Discussion}

The results of Experiment 1 demonstrated that prior discourse-level information can affect initial lexical activation. Recall that the second sentences containing the terminal homonyms were rated as being ambiguous (supporting both meanings) and that they activated both senses of an ambiguity in previous research when presented in isolation (Vu et al., 1998). Here, however, only the contextually appropriate sense of an ambiguous word was activated in the presence of unbiased local contexts. Therefore, the influence of context must derive from the level of the discourse. On the basis of research on discourse construction and sentence resolution, we surmise that ambiguity resolution in Experiment 1 was accomplished by a mapping of the ambiguous sentence to the semantic representation of the first sentence. When larger segments of discourse are encountered during comprehension, it is necessary to construct a coherent global discourse representation in order to distinguish the text from a collection of independent sentences (cf. Altmann, 1987; Crain \& Steedman, 1985; Just \& Carpenter, 1987; Sanford \& Garrod, 1981). To do so, each sentence encountered is evaluated and its meaning resolved in relation to prior discourse. The resolution of a sentence against its discourse context has been conceptualized as an anchoring (Garrod \& Sanford, 1994) or grounding process (Just \& Carpenter, 1987), in which new information is mapped onto the existing discourse representation. In the present experiment, the ambiguous sentences were anchored and evaluated against the semantic representation of the initial sentences. The prior discourse provided a referent for the pronoun of the second sentence, as well as biasing information to resolve the ambiguous word.
Vu et al. (1998) were able to identify the subject noun and verb of simple sentences as sources of constraint on lexical ambiguity resolution by systematically manipulating only these lexical categories. Such systematic isolation of constraints was not pursued in the present research. Consequently, it is more difficult to speculate on the specific sources of constraint affecting ambiguity resolution, except to say that the source(s) must derive from the prior global context because the local context provided no information that would enable one to prefer one interpretation of the ambiguous word over the other. We speculate that pragmatic constraints played a role, in part, in resolving the ambiguous words in Experiment 1. Consider the two alternative passages for the ambiguous word pass:

The rookie raised his hands.

He received the pass.

The caller won the contest.

He received the pass.

In these passages, either agent (rookie or caller), being animate and human, can plausibly receive either type of pass (e.g., football or ticket). However, on the basis of general world knowledge and the given discourse information, the reader infers the type of pass that a caller is more likely to receive. This represents (at least) a pragmatic constraint on the resolution of lexical ambiguity.

The pattern of word meaning activation in Experiment 1 is consistent with the context-sensitive model. Apparently, processing of each passage resulted in a specific global discourse representation that was compatible with only one interpretation of the homonym. This outcome agreed with participants' ratings of the stimuli, in that passages rated as strongly biased toward either the dominant or the subordinate sense of the homonym resulted in activation of only the contextually appropriate meaning. The results are incompatible with the reordered access model of ambiguity resolution and refute the general assumption that only local context can influence initial meaning activation processes while global context affects only the process of text integration (e.g., Binder \& Morris, 1995; Rayner et al., 1994; see also Kintsch \& Mross, 1985). If the latter were the case, multiple activation should have been evident immediately following the homonym of the ambiguous second sentence.

An argument could be raised that the evidence for ambiguity resolution did not occur on line. Because we employed word-by-word reading measures, it could be argued that the rate of presentation was too slow and that the 0 -msec ISI between homonym termination and target presentation was an insufficient test of initial meaning activation. It may be the case that individualized presentation rates resulted in an extended exposure duration of the terminal homonym (i.e., its SOA). The problem associated with a prolonged SOA is that within the time during which 
the homonym is presented, activation of multiple meanings followed by integration of the contextually appropriate meaning might have occurred prior to response execution (cf. Seidenberg et al., 1982; Tabossi \& Zardon, 1993; see also Marslen-Wilson \& Tyler, 1980). However, a literature search confirms that our average calibrated presentation rate of $266 \mathrm{msec}$, and thus homonym SOA exposure, was comparable to the average gaze duration on critical words ( $\sim 250$ to $300 \mathrm{msec})$ and was well within the boundaries of customary presentation rates used in the literature, ranging from Duffy, Henderson, and Morris (1989), 250 msec per word; Paul et al. (1992), $263 \mathrm{msec}$ per word (averaged across three experiments); Simpson and Krueger (1991) and Simpson, Peterson, Casteel, and Burgess (1989), 300 msec; Till, Mross, and Kintsch (1988), $333 \mathrm{msec}$; O'Seaghdha (1989), $400 \mathrm{msec}$; up to Stanovich and West (1983), with $500 \mathrm{msec}$ per word. Given these presentation rates, we submit that our calibrated presentation rate did not compromise the results. Nevertheless, our position is open to argument.

\section{EXPERIMENT 2}

It is generally accepted that multiple activation occurs at a 0 -msec ISI between offset of the ambiguous word and onset of the target word, and that selection of the appropriate meaning occurs within $200 \mathrm{msec}$ after homonym offset (see, e.g., Seidenberg et al., 1982). In the present experiment, a 0 -msec ISI between homonym and target was maintained. However, to further ensure the immediacy of meaning activation, we limited the exposure duration of the passage-final ambiguous word to an $80-\mathrm{msec}$ SOA. If ambiguity resolution does not occur immediately, and global context affects only a later stage of meaning integration, then severely limiting the exposure duration of the terminal homonym should provide evidence for the activation of multiple meanings. However, we predicted that even with an SOA of $80 \mathrm{msec}$, selective activation of a homonym's meanings would occur because the strongly biased passages would have immediately constrained the contextually appropriate meaning.

\section{Method}

Participants. The participants were 48 undergraduates from an introductory psychology course. All of them received class credit for participation and were native English speakers with normal or corrected-to-normal vision.

Stimuli. The stimuli used were from Experiment 1.

Apparatus and Procedure. These were identical to those of Experiment 1 with one exception. As before, the participants' reading rate was calibrated. The calibrated rate was subsequently used in the experimental trials but not for presentation of the terminal homonym, which lasted only $80 \mathrm{msec}$. Immediately following the offset of the homonym ( 0 -msec ISI), the target word was presented.

\section{Results}

Two participants were replaced because of a high rate of comprehension errors ( $>40 \%$ ), and 2 participants were replaced because of excessive naming errors $(>10 \%)$. The participants' average calibrated reading rate was $285 \mathrm{msec}$ per word $(S D=42 \mathrm{msec})$. Naming errors constituted only $3.8 \%$ of the total data and were excluded from subsequent analyses. Comprehension accuracy was $81.5 \%$.

Mean naming latencies were submitted to a discourse bias $\times$ target dominance $\times$ target relatedness analysis of variance for repeated measures, with both participants $\left(F_{1}\right)$ and items $\left(F_{2}\right)$ as random variables. All effects to be reported here were significant at $p<.05$ unless otherwise indicated. The mean naming latencies, percent errors, and magnitude of priming are presented in Table 2.

Table 2 shows that naming latencies for contextually appropriate target words following both dominant and subordinate primes were facilitated relative to unrelated conditions, while latencies for inappropriate targets were not. Again there were reliable effects of target dominance, target relatedness, and an interaction of discourse bias $\times$ target dominance. These effects were qualified by the interaction of discourse bias $\times$ target dominance $\times$ target relatedness $\left[F_{1}(1,47)=14.62, M S_{\mathrm{e}}=789.81 ; F_{2}(1,95)=\right.$ $\left.8.70, M S_{\mathrm{e}}=2,823.24\right]$. The three-way interaction was examined further by evaluating target dominance $\times$ target relatedness for each discourse bias separately. As in Experiment 1, for the dominant bias condition, there was a reliable interaction of target dominance $\times$ target relatedness $\left[F_{1}(1,47)=7.20, M S_{\mathrm{e}}=679.17\right.$, but $F_{2}(1,95)=$ $\left.2.77, M S_{\mathrm{e}}=4,026.17 ; p=.10\right]$. As Table 2 indicates, responses to dominant targets were facilitated following dominant biased passages relative to responses to unrelated targets $[t(47)=4.69]$. On the other hand, responses to subordinate targets showed no facilitation relative to responses to unrelated targets $[t(47)=1.30, p>.20]$. Naming latencies for the subordinate bias condition showed an opposite pattern. Again, there was an interaction of target dominance $\times$ target relatedness $\left[F_{1}(1,47)\right.$ $\left.=8.67, M S_{\mathrm{e}}=776.68 ; F_{2}(1,95)=4.98, M S_{\mathrm{e}}=2,702.68\right]$. As Table 2 shows, with subordinate biased passages, responses to subordinate targets were facilitated relative to responses to unrelated targets $[t(47)=4.17]$. Alternatively, responses to dominant targets were not facilitated relative to responses to unrelated targets $[t(47)=.19, p>.50]$.

Again, a formal analysis of the error rates was not conducted. However, there was no evidence of a speedaccuracy tradeoff between naming latencies and error rates $(r=+.59)$.

\section{Discussion}

The results converged with those of Experiment 1, demonstrating activation of only the contextually appropriate meaning of a homonym even with an exposure duration of only $80 \mathrm{msec}$. This supports the argument that ambiguity resolution occurred immediately as part of an incremental reading process. If lexical ambiguity resolution had not occurred immediately on line, there would have been no basis for prior discourse $t \mathrm{~s}$ affect the resolution process, and target words related to both senses of the homonyms should have been primed. The results show that this was clearly not the case and are the opposite 
of what would be expected by the reordered access model or any assumption that global discourse affects only integration processes subsequent to meaning activation. Further support for the validity of word-by-word presentation and naming methodology can be found in the research of Altarriba, Kroll, Scholl, and Rayner (1996). They demonstrated that the pattern of naming latency data following a rapid serial visual presentation mode of presentation replicated data from first-pass fixations measured with eye-tracking methodology.

Thus far we have shown that in order for the resolution of lexical ambiguity to be possible, the ambiguous sentence must be anchored and resolved against its global discourse representation. It was the construction of a coherent global discourse representation of the two sentences that provided the information necessary to bias the homonym. We obtained additional support for this assertion by conducting a third experiment in which the experimental passages were separated and presented as null (i.e., isolated) sentences (cf. Altmann, 1987; Altmann \& Steedman; 1988; Crain \& Steedman, 1985). We predicted that without benefit of prior discourse, a representation must be constructed from the null context, and if the information was ambiguous, the homonym would remain unresolved.

\section{EXPERIMENT 3}

We predicted that without the construction of a coherent global discourse, the pattern of activation demonstrated in Experiments 1 and 2 would not be replicated. Instead we predicted that following each passage's first sentence presented in isolation, there would be no activation of any meaning related to the homonyms used in Experiments 1 and 2. These sentences provided biasing information for the homonyms only insofar as a coherent discourse representation of both sentences was constructed. In isolation, these sentences would not be related to the previously used target words. Following the second null sentence from the passages, there would be no prior discourse against which the ambiguous sentence might be interpreted. Therefore, multiple activation was predicted to occur because there was no biasing context and the sentences per se had been previously rated as supporting both meanings of the homonyms (Vu et al., 1998).

\section{Method}

Participants. The participants were 48 undergraduate volunteers from introductory psychology courses. All received class credit for participation and were native English speakers with normal or corrected-to-normal vision. The participants were randomly assigned to conditions and tested individually.

Stimuli. For this experiment, the 192 dominant and subordinate biasing passages ( 96 each) from Experiment 1 were separated into individual sentences. Since the second sentence of the dominant biasing passage was identical to the second sentence of the subordinate biasing passage, there were only 288 unique sentence primes In keeping with the terminology of Experiment 1, the 192 initia sentences were considered nominally dominant and subordinate biasing primes ( 96 each), although these sentences were predicted to be unrelated to any subsequent target word. The 96 second sentences were ambiguous primes.

Each prime type (dominant, subordinate, ambiguous) was paired with two associated target words (dominant, subordinate). The target words associated with each homonym were identical to those in Experiment 1 . Unrelated conditions were created by randomly repairing related primes and targets, with no prime or target being repeated within participants. To ensure that each prime and target appeared only once per participant with each participant exposed to all conditions, 12 stimulus lists were constructed. Each list consisted of an equal number of 12 possible prime-target conditions, with eight homonyms per condition, resulting in a total of 96 experimental trials per list. Procedures for selection of the 24 calibration trials and 36 practice trials were identical to those of Experiment 1. Examples of the conditions associated with Experiment 3 are presented in Table 3.

Apparatus and Procedure. Both the apparatus and procedure for Experiment 3 were the same as in Experiment 1 . The only notable difference was that in this experiment participants read single sentences instead of short passages.

\section{Results}

One participant was replaced because of a high rate of comprehension errors $(>40 \%)$, and 1 participant was replaced because of excessive naming errors $(>10 \%)$. The participants' average calibrated reading speed was $230 \mathrm{msec}$ per word $(S D=37 \mathrm{msec})$. Naming errors constituted only $2.6 \%$ of the total data and were excluded from subsequent analyses. Comprehension accuracy was $87.7 \%$.

Mean correct naming latencies were subjected to a prime type $\times$ target dominance $\times$ target relatedness analysis of variance for repeated measures, with both participants $\left(F_{1}\right)$ and items $\left(F_{2}\right)$ as random variables. All effects reported were significant at $p<.05$ unless otherwise indicated. The mean naming latencies, percent errors, and magnitude of priming are presented in Table 4.

There were reliable effects of target relatedness and prime type, qualified by the interaction of prime type $\times$ target relatedness $\left[F_{1}(2,94)=8.86, M S_{\mathrm{e}}=1,098.56\right.$; $\left.F_{2}(2,190)=6.90, M S_{\mathrm{e}}=2,528.53\right]$. As expected, the prime type $\times$ target dominance $\times$ target relatedness interaction was not significant $\left[F_{1}(2,94)=.59, M S_{\mathrm{e}}=\right.$ $1,355.05, p>.55 ; F_{2}(2,190)=.39, M S_{\mathrm{e}}=3,518.83, p>$ .67]. Examination of the prime type $\times$ target relatedness interaction revealed that there was an effect of target relatedness only following the ambiguous primes $\left[F_{1}(1,47)=19.94, M S_{\mathrm{e}}=1,266.36 ; F_{2}(1,95)=12.42\right.$, $\left.M S_{\mathrm{e}}=3,661.81\right]$. As Table 4 indicates, following nominally "dominant" and "subordinate" sentence primes (i.e.,

Table 3

Examples of Prime and Target Stimuli Across All Conditions in Experiment 3

\begin{tabular}{llll}
\hline \multicolumn{1}{c}{ Bias } & \multicolumn{1}{c}{ Sentence Primes } & Related & Unrelated \\
\hline $\begin{array}{l}\text { Dominant } \\
\text { Subordinate }\end{array}$ & The rookie raised his hands. & FOOTBALL & CAR \\
Ambiguous & He received the pass. & TICKET & ASSAULT \\
$\begin{array}{l}\text { Dominant } \\
\text { Subordinate } \\
\text { Ambiguous }\end{array}$ & $\begin{array}{l}\text { The technician was incompetent. } \\
\text { The overlooked the battery. }\end{array}$ & CAR was lenient. & FOOTBALL \\
& & & \\
\end{tabular}


Table 4

Mean Naming Latencies (in Milliseconds), Percent Errors, and Magnitude of Priming for Experiment 3

\begin{tabular}{|c|c|c|c|c|c|c|c|c|c|c|c|c|}
\hline \multirow[b]{4}{*}{ Target } & \multicolumn{12}{|c|}{ Sentence Prime } \\
\hline & \multicolumn{4}{|c|}{ Ambiguous } & \multicolumn{4}{|c|}{ Dominant } & \multicolumn{4}{|c|}{ Subordinate } \\
\hline & \multicolumn{2}{|c|}{$\begin{array}{c}\text { Dominant } \\
\text { Target }\end{array}$} & \multicolumn{2}{|c|}{$\begin{array}{c}\text { Subordinate } \\
\text { Target }\end{array}$} & \multicolumn{2}{|c|}{$\begin{array}{c}\text { Dominant } \\
\text { Target }\end{array}$} & \multicolumn{2}{|c|}{$\begin{array}{c}\text { Subordinate } \\
\text { Target }\end{array}$} & \multicolumn{2}{|c|}{$\begin{array}{c}\text { Dominant } \\
\text { Target }\end{array}$} & \multicolumn{2}{|c|}{$\begin{array}{c}\text { Subordinate } \\
\text { Target }\end{array}$} \\
\hline & $M$ & $\% \mathrm{E}$ & $M$ & $\% \mathrm{E}$ & $M$ & $\% \mathrm{E}$ & $M$ & $\% \mathrm{E}$ & $M$ & $\% \mathrm{E}$ & $M$ & $\% \mathrm{E}$ \\
\hline Unrelated & 686 & 2.3 & 693 & 3.1 & 705 & 2.9 & 707 & 3.6 & 704 & 2.6 & 702 & 2.9 \\
\hline Related & 666 & 1.3 & 667 & 2.3 & 699 & 3.4 & 707 & 2.9 & 713 & 1.3 & 703 & 2.6 \\
\hline Priming & \multicolumn{2}{|c|}{$20^{*}$} & \multicolumn{2}{|c|}{$26^{*}$} & \multicolumn{2}{|c|}{6} & \multicolumn{2}{|c|}{0} & \multicolumn{2}{|c|}{-9} & \multicolumn{2}{|c|}{-1} \\
\hline
\end{tabular}

first sentences of the earlier passages), there were no differences between related and unrelated target words. However, naming latencies for both dominant and subordinate target words were facilitated relative to latencies for unrelated targets following ambiguous sentence primes.

Again, Pearson's correlation coefficient comparing naming latencies with error rates provided no evidence of a speed-accuracy tradeoff $(r=+.000)$.

\section{Discussion}

The results of Experiment 3 confirmed our predictions. Presentation of null contexts did not replicate the pattern of activation found for Experiments 1 and 2. Instead, when the initial sentences were used as primes in isolation, no differences were obtained between naming latencies for previously related and unrelated target words. When the ambiguous sentences were presented in isolation, activation of both dominant and subordinate meanings of the homonyms was evident. Apparently, the information contained in the global discourse representation differs from what was represented by the sentences in isolation. This confirms that the results of Experiments 1 and 2 were due to the construction of coherent discourse-level representations and further supports the assumption of on-line lexical processing and the immediate resolution of lexical ambiguity by global context.

In sum, our research provides evidence that global discourse can immediately influence the resolution of lexical ambiguity. When an ambiguous sentence that has been demonstrated to support multiple meanings in isolation (Vu et al., 1998; Experiment 3 above) is represented within a global discourse representation, only one meaning is activated, depending on the intended bias of the discourse context.

\section{GENERAL DISCUSSION}

This series of experiments provides evidence that global discourse can immediately influence the process of lexical ambiguity resolution. Experiment 1 demonstrated that even in the face of unbiased local contexts, selective activation of the context-appropriate meaning of an ambiguous word was obtained. Because the local contexts were ambiguous and supported both dominant and subordi- nate meanings of the homonyms, the influence of context must derive from the level of the discourse. Experiment 2 provided stronger confirmation of the immediacy of the resolution process by replicating the results of Experiment 1 with a homonym exposure duration of only $80 \mathrm{msec}$. The use of an $80-\mathrm{msec}$ SOA for the ambiguous word in conjunction with a 0 -msec ISI interval between presentation of the homonym and target word is well within the temporal window proposed for the activation of multiple meanings (e.g., Seidenberg et al., 1982). Despite these temporal restrictions, selective activation of the ambiguous words was obtained. Experiment 3 verified that it was the integration of the two sentences into a discourse-level representation that provided the constraints necessary for ambiguity resolution to occur. When the initial sentences were presented in isolation, no activation was found for previously related target words as compared with unrelated ones. And, when the ambiguous sentences were presented in isolation, multiple senses of the ambiguous words were activated. Failure to demonstrate selective activation following either sentence-level representation suggests that information contained in the first sentence was only effective for ambiguity resolution insofar as it was integrated with the second sentence to produce a global discourse representation.

The results are compatible with the context-sensitive model of lexical ambiguity resolution. According to this constraint-based approach (cf. Marslen-Wilson \& Tyler, 1987; McClelland, 1987), the resolution of lexical ambiguity is dependent on the amount of evidence (constraints) that accumulates in support of one or the other meaning of an ambiguous word. The processing of discourse is conceptualized as a dynamic interaction between the evolving semantic representation and each subsequent lexical input that is mapped onto the representation. The incremental mapping of each input constrains the overall representation, which in turn provides a constraint on the next lexical input. Thus, comprehension of a text is a process of constraint satisfaction that occurs for sentence contexts as well as for larger discourse. As long as the constraints converging on an ambiguous word are sufficiently strong, selective activation of the context-appropriate meaning will occur, regardless of whether the constraints arise from the local or more global discourse context. 
Our results are incompatible with the reordered access model with respect to two proposals. For the reordered access model, (1) global discourse information cannot influence processing of an ambiguous word at the local level (Rayner et al., 1994) and (2) the activation of multiple meanings is expected in all contexts, regardless of contextual bias (cf. Duffy et al., 1988). Given either assumption, multiple activation of an ambiguous word would be predicted in the presence of the passages that we employed. In Experiments 1 and 2, if only local contexts affected ambiguity resolution, multiple activation should have been obtained because the ambiguous words were embedded in local contexts that supported both dominant and subordinate meanings.

The results of the present research are also contrary to recent work examining the effect of global discourse on lexical ambiguity resolution. Rayner et al. (1994) employed passages in which a polarized ambiguous word occurred twice in its same sense with the global and local context biasing the subordinate meaning. Control passages were constructed by replacing the ambiguous word with an unambiguous word that fit semantically with the context. Gaze duration on the second occurrence of the ambiguous word was examined and compared with that for the unambiguous word. The expectation was that processing of the polarized ambiguous word would be facilitated, compared with that for the unambiguous word, if global context influenced ambiguity resolution. Since reading time on the ambiguous word was not facilitated in comparison with that for the control word, the conclusion drawn was that global context does not influence processing of an ambiguous word. However, comparing reading times on ambiguous and unambiguous words may potentially obscure global contextual influence on ambiguity resolution. First, a matched unambiguous control word may be processed faster than a polarized ambiguous word in a subordinate bias context because an unambiguous word has no alternate at the meaning level that is competing for activation. Second, we note that in Rayner et al., the control word was also repeated and contextually constrained, and research has demonstrated that strong contextual constraints (e.g., Rayner \& Well, 1996; Schwanenflugel \& LaCount, 1988; Schwanenflugel \& Shoben, 1985), and word repetition (e.g., Bainbridge, Lewandowsky, \& Kirsner, 1993; Binder \& Morris, 1995; Simpson \& Kellas, 1989), can facilitate processing of an unambiguous word. Consequently, the influence of global context on ambiguity resolution may have been masked by a similar influence of global context (and word repetition) on the unambiguous control words.

Binder and Morris (1995, Experiment 2) constructed global contexts that included two occurrences of a homonym used in its same subordinate sense, but the discourse topic was either maintained or shifted upon the second encounter of the homonym. It was expected that maintaining the topic would result in faster processing of the repeated homonym, because prior discourse information would be available for use. However, when the topic was shifted, processing of the repeated homonym was expected to be delayed, because prior discourse information would not be available. The results showed that the topic manipulation did not affect processing of the repeated homonym, leading to the conclusion that global context cannot influence lexical activation processes. However, the results of Binder and Morris's may not have ruled out an effect of global context. Binder and Morris's conclusion rests on the assumption that for the topic shift condition, prior global discourse information was not available at the moment at which the homonym was encountered for the second time. This may not necessarily be the case. Although there was an internal topic shift, it only signified a different episode within the larger narrative theme. The sense of the homonym instantiated by the local context remained thematically consistent with the global context. It could well be that the compatibility of local and global contexts at the thematic level facilitated processing of the homonym repeated in its same sense.

It is unclear how local contexts can affect lexical activation processes but global contexts cannot, unless one concludes that priming effects observed in local contexts must originate from intralexical priming (see, e.g., Rayner et al., 1994). Several researchers, however, have provided evidence that intralexical priming of associates cannot fully explain the magnitude or duration of priming observed at the sentence level (e.g., Dopkins et al., 1992; O'Seaghdha, 1989, 1991; Simpson et al., 1989; Van Petten, Weckerly, McIsaac, \& Kutas, 1997; Vu et al., 1998) or the discourse level (e.g., Foss, 1982; Foss \& Speer, 1991; Hess et al., 1996; Sharkey \& Sharkey, 1992). Instead of differentiating between the effects of local versus global contexts, the context-sensitive position acknowledges the immediate influence of context at all levels. Regardless of whether the context is a sentence or larger discourse, the mapping of lexical input proceeds incrementally to produce a semantic representation that can constrain interpretation of an ambiguous word encountered in strongly biased contexts.

There are two issues that may be of concern to the interpretation of our results. One issue is whether or not the naming latencies that we obtained in the present research were unusually long. A literature search showed that our naming latencies were comparable to those of published research supporting the positions of interactive activation and modularity. For example, naming latencies for target words presented immediately following an ambiguous word in context ranged from Seidenberg et al. (1982, Experiment 1), $672 \mathrm{msec}$; Stanovich and West (1983, Experiment 1), $686 \mathrm{msec}$; Tanenhaus et al. (1979), $695 \mathrm{msec}$; Altarriba et al. (1996), $744 \mathrm{msec}$; up to Stanovich and West (1981, Experiment 3), $819 \mathrm{msec}$. It should be noted that Seidenberg et al. (1982) employed short four- and five-word sentences (e.g., If Joe buys the straw), yet recorded naming latencies ranging from 650 to $705 \mathrm{msec}$. By contrast, the mean naming latency was $711 \mathrm{msec}$ (averaged across the three experiments) for our research. This included the average latency for Experi- 
ment 2 (773 msec), where normal reading was disrupted because of the 80 -msec presentation of the terminal homonym. Thus, we submit that our naming latencies are reasonable, considering that participants were required to read a passage, name a target word, and then immediately answer a $w h$-comprehension question about the passage.

The concern of relatively long naming latencies centers on the possibility that readers may have activated multiple meanings and integrated the contextually appropriate meaning during and after reading of the terminal homonym prior to response execution. Thus, long naming latencies reflect the outcome only of meaning selection, and not of priming. ${ }^{4}$ This possibility is a rather difficult position to defend against, because meaning selection can always be argued in lieu of meaning activation. For interactive models, the so-called access and integration processes are simultaneously achieved with the incremental processing of each lexical input. Certainly, as participants move toward response execution, partial integration of an ambiguous word with prior context will have been achieved. In theory, however, there should be some detection of multiple senses if meaning activation is immediately assessed (cf. Fodor, 1983; Forster, 1979). The onus continues to be on research supporting selective activation to disprove the selection hypothesis, because, realistically, the temporal window for capturing multiple activation can always be shortened to preserve the principles of modularity. However, if the activation-selectionintegration process occurs so quickly that it cannot be detected and/or separated, the language comprehension system is functionally interactive (cf. Carpenter, Miyake, \& Just, 1995).

Finally, the point could be made that the priming observed in Experiments 1 and 2 might have reflected priming from the context preceding the ambiguous word and not the global text representation in its entirety. For example, following the discourse frame "The rookie raised his hands. He received ...," the target word FOOTBALL might have been primed but not TICKET. We doubt that the selective pattern of activation obtained in Experiments 1 and 2 would be replicated with the use of incomplete passage fragments because of the results of Experiment 3 . No relationship was established between target words and the first sentences presented in isolation, whereas the ambiguous sentences established a relationship with both meanings. This suggests that priming of only the contextually appropriate targets (i.e., selective priming) requires a convergence of prior information from the initial sentences with information contained in the second sentence including the ambiguous word. The relationship between a target with its dominant (or subordinate) passage is realized only in the presence of an ambiguous word. Consequently, presentation of passage fragments would probably show no relationship to target words that have an empirical association with the deleted ambiguous words. As noted, we presented participants with passage fragments that eliminated the final ambiguous words using cloze procedures. The results demonstrated that ambiguous words and their associated target words were rarely given as completions of the passage frames. ${ }^{5}$

\section{Conclusion}

Given that we were within the temporal window for detecting multiple activation by using a 0 -msec ISI between homonym and target word presentation, and an 80-msec SOA (Experiment 2), and the fact that our naming latencies were typical of those reported in the literature for connected discourse, we conclude that global discourse information can immediately influence the resolution of lexical ambiguity. The results of the present research are compatible with a multiple-constraint satisfaction process implemented in many interactive activation models of language processing (e.g., Taraban \& McClelland, 1988). The context-sensitive model is able to handle, more consistently, the full range of data available from research on lexical ambiguity resolution. According to our proposal, the activation level of word meanings is a joint product of multiple constraints that includes, but is not limited to, meaning frequency, the type of biasing context, and the strength of biasing context. On this view, different patterns of meaning activation including selective, exhaustive, and frequency ordered activation are possible, depending on different constraints and contingent on the strength of the biasing contexts. The influence of these constraints can be realized through local contexts as well as larger segments of discourse.

\section{REFERENCES}

Altarriba, J., Kroll, J., Scholl, A., \& Rayner, K. (1996). The influence of lexical and conceptual constraints on reading mixedlanguage sentences: Evidence from eye fixations and naming times. Memory \& Cognition, 24, 477-492.

ALTMANN, G. T. M. (1987). Modularity and interaction in sentence processing. In J. Garfield (Ed.), Modularity in knowledge representation and natural language processing (pp. 428-444). Cambridge, MA: MIT Press.

Altmann, G. T. M., \& Steedman, M. (1988). Interaction with context during human sentence processing. Cognition, 30, 191-238.

Bainbridge, J. V., Lewandowsky, S., \& Kirsner, K. (1993). Context effects in repetition priming are sense effects. Memory \& Cognition, 21, 619-626.

BindER, K. S., \& MoRris, R. K. (1995). Eye movements and lexical ambiguity resolution: effects of prior encounter and discourse topic. Journal of Experimental Psychology: Learning, Memory, \& Cognition, 21, 1186-1196.

Carpenter, P. A., Miyake, A., \& Just, M. A. (1995). Language comprehension: Sentence and discourse processing. Annual Review of Psychology, 46, 91-120.

Crain, S., \& Steedman, M. J. (1985). On not being led up the garden path: The use of context by the psychological parser. In D. Dowty, L. Karttunen, \& A. Zwicky (Eds.), Natural language parsing: Psychological, computational, and theoretical perspectives (pp. 320-359). Cambridge: Cambridge University Press.

Dell, G. S., MCKoon, G., \& RatClifF, R. (1983). The activation of antecedent information during the processing of anaphoric reference in reading. Journal of Verbal Learning \& Verbal Behavior, 22, 121-132.

Dopkins, S., Morris, R. K., \& RAYNER, K. (1992). Lexical ambiguity and eye fixation in reading: A test of competing models of lexical ambiguity resolution. Journal of Memory \& Language, 31, 461-476. 
Duffy, S. A., Henderson, J. M., \& Morris, R. K. (1989). Semantic facilitation of lexical access during sentence processing. Journal of $E x$ perimental Psychology: Learning, Memory, \& Cognition, 15, 791-801

DufFy, S. A., MORRIS, R. K., \& RAYNER, K. (1988). Lexical ambiguity and fixation times in reading. Journal of Memory \& Language, 27, 429-446.

FoDoR, J, A. (1983). Modularity of mind. Cambridge, MA: MIT Press. FORSTER, K. I. (1979). Levels of processing and the structure of the language processor. In W. E. Cooper \& E. Walker (Eds.), Sentence processing: Psycholinguistic studies presented to Merrill Garrett (pp. $27-$ 85). Hillsdale, $\mathrm{NJ}$ : Erlbaum.

Foss, D. J. (1982). A discourse on semantic priming. Cognitive Psychology, 14, 590-607.

Foss, D. J., \& SPEer, S. R. (1991). Global and local context effects in sentence processing. In R. Hoffman \& D. Palermo (Eds.), Cognition and the symbolic processes: Vol. III. Applied and ecological perspectives (pp. 115-139). Hillsdale, NJ: Erlbaum.

GARROD, S. C., \& SANFORD, A. J. (1994). Resolving sentences in a discourse context. In M. A. Gernsbacher (Ed.), Handbook of psycholinguistics (pp. 675-698). San Diego: Academic Press.

Greene, S. B., MCKoon, G., \& Ratcliff, R. (1992). Pronoun resolution and discourse models. Journal of Experimental Psychology. Learning, Memory, \& Cognition, 18, 266-283.

Hess, D. J., Foss, J. F., \& CARROLl, P. (1996). Effects of global and local context on lexical processing during language comprehension. Journal of Experimental Psychology: General, 124, 62-82.

JuST, M. A., \& CARPENTER, P. A. (1987). Understanding the referent of a text. In M. A. Just \& P. A. Carpenter (Eds.), The psychology of reading and language comprehension (pp. 195-223). Newton, MA: Allyn \& Bacon.

Just, M. A., Carpenter, P. A., \& Woolley, J. D. (1982). Paradigms and processes in reading comprehension. Journal of Experimental Psychology: General, 111, 228-238.

KaWAMOTO, A. H. (1993). Nonlinear dynamics in the resolution of lexical ambiguity: A parallel distributed processing account. Journal of Memory \& Language, 32, 474-516.

Kellas, G., Paul, S. T., Martin, M., \& Simpson, G. B. (1991). Contextual feature activation and meaning access. In G. B. Simpson (Ed.), Understanding word and sentence (pp. 47-71). Amsterdam: Elsevier

KinTSCH, W., \& Mross, E. F. (1985). Context effects in word recognition. Journal of Memory \& Language, 8, 336-344.

KUČERA, H., \& FRANCIS, W. (1967). Computational analysis of presentday American English. Providence, RI: Brown University Press.

MARSLEN-WILSON, W., \& TYLER, L. K. (1980). The temporal structure of spoken language understanding. Cognition, 8, 1-71.

MarsLen-WiLsON, W., \& TYLER, L. K. (1987). Against modularity. In J. Garfield (Ed.), Modularity in knowledge representation and natural language understanding (pp. 37-62). Cambridge, MA: MIT Press

Martin, C., Vu, H., Kellas, G., \& Metcalf, K. (1999). Strength of context as a determinant of the subordinate bias effect. Quarterly Journal of Experimental Psychology, 52A, 813-839

Massaro, D., TAYlor, G., Venezky, R., Jastrzembski, J., \& LuCAS, P. (1980). Letter and word perception: The role of orthographic structure and visual processing in reading. Amsterdam: North-Holland

MCClelland, J. L. (1987). The case for interactionism in language processing. In M. Coltheart (Ed.), Attention and performance XII: The psychology of reading (pp. 3-36). Hillsdale, NJ: Erlbaum.

McClelland, J. L., St. John, M., \& Taraban, R. (1989). Sentence comprehension: A parallel distributed processing approach. Language \& Cognitive Processes, 4, 287-335.

Nelson, D. L., McEvoy, C. L., WAlling, J. R., \& Wheeler, J. W., JR. (1980). The University of South Florida homograph norms. Behavior Research Methods \& Instrumentation, 12, 16-37.

ONIFER, W., \& SWINNEY, D. A. (1981). Accessing lexical ambiguities during sentence comprehension: Effects of frequency of meaning and contextual bias. Memory \& Cognition, 9, 225-236.

O'Seaghdha, P. G. (1989). The dependence of lexical relatedness effects on syntactic connectedness. Journal of Experimental Psychology: Learning, Memory, \& Cognition, 15, 73-87.

O'SEAGHDHA. P. G. (1991). A perspective on sentence context research.
In G. B. Simpson (Ed.), Understanding word and sentence (pp. 7396). Amsterdam: Elsevier.

PACHT, J. M., \& Rayner, K. (1993). The processing of homophonic homographs during reading: Evidence from eye movement studies. Journal of Psycholinguistic Research, 22, 251-271.

Paul, S. T., Kellas, G., Martin, M., \& Clark, M. B. (1992). Influence of contextual features on the activation of ambiguous word meanings. Journal of Experimental Psychology: Learning, Memory, \& Cognition, 18, 703-717.

RAYNER, K., \& Frazier, L. (1989). Selection mechanisms in reading lexically ambiguous words. Journal of Experimental Psychology: Learning, Memory, \& Cognition, 15, 779-790.

RAYNER, K., PACht, J. M., \& DuFFy, S. A. (1994). Effects of prior encounter and global discourse bias on the processing of lexically ambiguous words: Evidence from eye fixations. Journal of Memory \& Language, 33, 527-544.

RAYNER, K., \& WELL, A. D. (1996). Effects of contextual constraint on eye movements in reading: A further examination. Psychonomic Bulletin \& Review, 3, 504-509.

SANFORD. A. J., \& GaRROD, S. C. (1981). Understanding written language. New York: Wiley.

SCHWANENFlugel, P. J., \& LaCount, K. (1988). Semantic relatedness and the scope of facilitation for upcoming words in sentences. Journal of Experimental Psychology: Learning, Memory, \& Cognition, 14, 344-354.

Schwanenflugel, P. J., \& Shoben, E. J. (1985). The influence of sentence constraint on the scope of facilitation for upcoming words. Journal of Memory \& Language, 24, 232-252.

Seidenberg, M. S., Tanenhaus, M. K., Leiman, J. M., \& BienKOWSKI, M. (1982). Automatic access of the meanings of ambiguous words in context: Some limitations of knowledge-based processing. Cognitive Psychology, 14, 489-537.

Sharkey, A. J. C., \& Sharkey, N. E. (1992). Weak contextual constraints in text and word priming. Journal of Memory \& Language, 31, 543-572.

Simpson, G. B. (1981). Meaning dominance and semantic context in the processing of lexical ambiguity. Journal of Verbal Learning \& Verbal Behavior, 20, 120-136.

Simpson, G. B., \& Kellas, G. (1989). Dynamic contextual processes and lexical access. In D. S. Gorfein (Ed.), Resolving semantic ambiguity (pp. 40-56). New York: Springer-Verlag.

Simpson, G. B., \& KRUEGER, M. A. (1991). Selective access of homograph meanings in sentence context. Journal of Memory \& Language, 30 , $627-643$

Simpson, G. B., Peterson, R. R., Casteel, M. A., \& Burgess, C. (1989). Lexical and sentence context effects in word recognition. Journal of Experimental Psychology: Learning, Memory, \& Cognition, 15, 88-97.

Stanovich, K. E., \& WEST, R. F. (1981). The effect of sentence context on ongoing word recognition: Tests of a two-process theory. Journal of Experimental Psychology: Human Perception \& Performance, 3 , 658-672.

STANOVICH, K. E., \& WEST, R. F. (1983). On priming by a sentence context. Journal of Experimental Psychology: General, 112, 1-36.

SWINNEY, D. A. (1979). Lexical access during sentence comprehension: (Re)consideration of context effects. Journal of Verbal Learning \& Verbal Behavior, 18, 645-659.

TABOSSI, P. (1988). Effects of context on the immediate interpretation of unambiguous nouns. Journal of Experimental Psychology: Learning, Memory, \& Cognition, 14, 153-162.

TABossı, P., Colombo, L., \& JoB, R. (1987). Accessing lexical ambiguity: Effects of context and dominance. Psychological Research, 49, 161-167.

TABOSSI, P., \& ZARDON, F. (1993). Processing ambiguous words in context. Journal of Memory \& Language, 32, 359-372.

Tanenhaus, M. K., Leiman, J. M., \& Seidenberg, M. S. (1979). Evidence for multiple stages in the processing of ambiguous words in syntactic contexts. Journal of Verbal Learning \& Verbal Behavior, $18,427-440$

Taraban, R., \& MCClelland, J. L. (1988). Constituent attachment 
and thematic role assignment in sentence processing: Influences of content-based expectations. Journal of Memory \& Language, 27, 597-632.

Till, R. E., Mross, E. F., \& Kintsch, W. (1988). Time course of priming for associate and inference words in a discourse context. Memory \& Cognition, 16, 283-298.

TWILley, L. C., Dixon, P., TAYlor, D., \& Clark, K. (1994). University of Alberta norms of relative meaning frequency for 566 homographs. Memory \& Cognition, 22, 111-126.

Van Petten, C., \& Kutas, M. (1987). Ambiguous words in context: An event-related potential analysis of the time course of meaning activation. Journal of Memory \& Language, 26, 188-208.

Van Petten, C., Weckerly, J., McIsaac, H. K., \& Kutas, M. (1997). Working memory capacity dissociates lexical and sentential context effects. Psychological Science, 8, 238-242.

Vu, H., Kellas, G., \& Paul, S. T. (1998). Sources of sentence constraint on lexical ambiguity resolution. Memory \& Cognition, 26, 979-1001.

\section{NOTES}

1. Seidenberg et al. (1982) proposed that word-based priming from within the lexicon could account for their results. However, several studies (see the General Discussion) have since demonstrated that the mechanism of intralexical priming cannot fully explain priming effects observed in sentence and discourse contexts.

2. The terms lexical access, activation, retrieval, and availability of word meanings are temporally related and often indiscriminately interchanged in the literature. It is not the intent of this paper to clarify these terms beyond what is currently available in the literature. Henceforth, for consistency, we refer to the activation of word meanings for the remainder of the manuscript, except when we describe specific models that adhere to different terminology.

3. We assume a minimalist approach for defining local versus global contexts. Operationally, we define a local context simply as the sentence that contains an ambiguous word, whereas a more global context contains information that is found outside of the local sentence-that is, information from the sentence preceding the local sentence.

4. Indeed, one reviewer suggested that the increase in naming latencies in Experiment 2 versus Experiment 1 might have circumvented the 80 -msec presentation rate of the ambiguous word. Proponents of modularity might argue that an increase in naming latencies would allow additional time to select between activated dominant and subordinate meanings. We would suggest, however, that the increase in latencies is an artifact of the disruption of the normal presentation rate calibrated for individual subjects. The abrupt termination of the ambiguous word possibly compounded the difficulty in switching attention to the naming task. In addition, Stanovich and West (1981) found support for exhaustive activation with naming latencies above $800 \mathrm{msec}$. A meaning selection hypothesis based on long naming latencies would suggest that selective activation should occur by $800 \mathrm{msec}$. Obviously, other factors are involved in lexical ambiguity resolution, one of which, we propose, is strength of context. Of course, an argument can always be made that the naming paradigm reflects exhaustive activation followed by meaning selection depending on the criterion set for the temporal window of a two-stage process.

5 . One reviewer suggested that although ambiguous words and targets were rarely given as cloze completions, this may not be indicative of whether or not the passage frames primed the target words in the absence of the ambiguous words. It may be the case that participants generated completions that were semantically related to the ambiguous words and/or target words. Consequently, these semantically related words could prime the target words via mediated priming without lexical ambiguity resolution. We scored the cloze data and found that probabilities for completions that were semantically related to the target words were .07 for dominant passage frames and .13 for subordinate passage frames. The low probability values for semantically related completions suggest that priming from the passage frames is an unlikely explanation for the data.

\section{APPENDIX \\ Dominant and Subordinate Biased Passages and Target Words (Dominant and Subordinate) Employed in Experiments 1 and 2}

For Experiment 3, each passage was separated into two individual sentences to yield a nominally "dominant" sentence and an ambiguous sentence, and a nominally "subordinate" sentence and the same ambiguous sentence.

Each pair of passages below is given according to the following pattern:

Dominant biased passages. "Dominant" sentence. [Ambiguous sentence.]

Subordinate biased passages. "Subordinate" sentence.

For each pair of passages, the first target word is dominant; the second, subordinate.

1. The center awaited the pass. She watched the ball.

The debutante sat by the door. She watched the ball.

2. The robber rushed out the door. He came from the bank.

The alligator saw the food. He came from the bank.

3. The renter heard the sound. She investigated the bark.

The botanist looked for a fungus. She investigated the bark.

4. The runner watched the throw. He approached the base.

The sergeant left the jeep. He approached the base.

5. The boy came from the dugout. He located the bat. The biologist searched the opening. He located the bat.

6. The technician was incompetent. He overlooked the battery.

The judge was lenient. He overlooked the battery.

7. The dieter lost weight. He deserved the belt.

The chauvinist was obnoxious. He deserved the belt.

8 . The waiter returned to the table. He wrote the bill.

The assistant proposed the idea. He wrote the bill.

bounce
dance
vault
river
growl
tree
safe
station
ball
cave
car
assault
pants
hit
pay
government




\section{APPENDIX (Continued)}

9. The carpenter used a saw. He divided the board. The chairman started the argument. He divided the board.

10. The contestant missed the mark. He straightened the bow. The groomsman looked in the mirror. He straightened the bow.

11. The visitor entered the kitchen. He spotted a bug. The detective searched the room. He spotted a bug.

12. The custodian found the solution. She inserted the bulb. The gardener dug a hole. She inserted the bulb.

13. The homemaker disliked the drawers. She rejected the cabinet. The queen ignored the advice. She rejected the cabinet.

14. The therapist entered the room. He delivered the cane. The harvester gathered the crop. He delivered the cane.

15. The clothier received the order. He manufactured the cap. The brewer started a bottling company. He manufactured the cap.

16. The dealer saw the markings. She exchanged the cards. The shopper disliked the poem. She exchanged the cards.

17. The laborer was thirsty. He finished a case. The counsel left the room. He finished a case.

18. The invalid was unable to move. She hated the cast. The reviewer was disappointed. She hated the cast.

19. The cashier saw a mistake. He reviewed the charge. The commander counted the fatalities. He reviewed the charge.

20. The medic finished the examination. He covered the chest. The sailor shoveled the sand. He covered the chest.

21. The teacher completed the tally. She knew the count. The duchess accepted the gift. She knew the count.

22. The navigator dropped the compass. He searched the deck. The gambler wanted an ace. He searched the deck.

23. The appraiser was skeptical. He measured the diamond. The groundskeeper was compulsive. He measured the diamond.

24. The housewife prepared too much. She saved the dough. The graduate wanted a car. She saved the dough.

25. The stuntman was experienced. He anticipated the fall. The yardman checked the weather. He anticipated the fall.

26. The planter sprayed insecticide. He rechecked the field. The referee miscounted. He rechecked the field.

27. The typist forgot the invoice number. She needed the file. The beautician was not finished. She needed the file.

28 . The traveler checked the itinerary. She counted the flights. The resident noted the broken elevator. She counted the flights.

29. The gourmet prepared the potatoes. He held the foil. The opponent awaited the signal. He held the foil.

30. The entertainer delighted the audience. He used the gag The kidnapper prevented the scream. He used the gag.

31. The star was injured. He observed the game. The woodsman was hunting. He observed the game.

32. The swimmer looked at the water. She noticed the glare. The comedian was offensive. She noticed the glare.

33. The vandal threw the rock. She broke the glass. The barmaid dropped the tray. She broke the glass.

34. The developer liked the area. He saved the grounds. The cook was thrifty. He saved the grounds.

35. The model had a rash. She hid her hand. The guest was cheating. She hid her hand.

\section{plank}

directors

arrow

tie

insect

microphone

light

flower

kitchen

minister

walking

sugar

hat

top

playing

greeting

beer

lawsuit

broken

actors

credit

attack

body

treasure

math

nobleman

ship

pack

ring

baseball

flour

money

down

leaves

farm

sports

cabinet

nail

plane

stairs

aluminum

sword

joke

mouth

play

animal

sun

stare

window

cup

dirt

coffee

fingers

cards 
APPENDIX (Continued)

36. The musician was up next. He grabbed the horn. The poacher reached for his kill. He grabbed the horn.

blow

deer

37. The blacksmith put on gloves. He carried the iron.

The businessman lived from a suitcase. He carried the iron.

38. The dietician made breakfast. He bypassed the jam.

The cabby knew the streets. He bypassed the jam.

39. The athlete lied about the play. He exaggerated the kick. The pusher lied about the product. He exaggerated the kick.

40. The spouse fixed dinner. He fed the kid. The zookeeper mixed the grain. He fed the kid.

41. The bird built a nest. She tore the leaf. The pianist flipped the page. She tore the leaf.

42. The decorator disliked the layout. He organized the lobby. The mayor helped the group. He organized the lobby.

43. The burglar used a hacksaw. He cut the lock. The hippie changed his appearance. He cut the lock.

44. The hermit made a chair. He used a log. The researcher transformed the data. He used a log.

45. The strongman was trembling. He held the mass. The bishop arrived on time. He held the mass.

46. The collector completed the set. He found a match. The boyscout searched his supplies. He found a match.

47. The cat was hunting. She observed the mole.

The dermatologist examined the skin. She observed the mole.

48. The wife put up the picture. She bent the nail. The manicurist was in a hurry. She bent the nail.

49. The fisherman bought the gear. He showed the net. The accountant subtracted the expense. He showed the net.

50. The secretary made the correction. She changed the note. The guitarist adjusted the string. She changed the note.

51. The pastor wanted livelier music. He refused the organ. The surgeon noted the damage. He refused the organ.

52. The hiker began the journey. He raised the pack. The ranger loved wildlife. He raised the pack.

53. The scholar knew the reference. He identified the page. The knight watched the procession. He identified the page.

54. The rookie raised his hands. He received the pass. The caller won the contest. He received the pass.

55. The guide was cautious. He marked the passage. The librarian found the quote. He marked the passage.

56. The stenographer took dictation. He emptied the pen. The farmer hated the smell. He emptied the pen.

57. The catcher flashed the signal. He changed the pitch. The singer raised his voice. He changed the pitch.

58. The busboy was clumsy. He bumped the pitcher. The coach changed the lineup. He bumped the pitcher.

59. The ecologist discovered a specie. He named the plant. The tycoon attended the opening. He named the plant.

60. The quarterback regained consciousness. He recollected the play. The screenwriter knew the lines. He recollected the play.

61. The realtor wanted to expand. He developed the plot. The writer changed the setting. He developed the plot.

62. The helmsman expected a storm. He recommended the port. The headwaiter scanned the list. He recommended the port. steel

shirt

toast

stuck

punt

stimulation

child

goat

maple

sheet

motel

legislative

key

hair

wood

arithmetic

weight

church

together

fire

rodent

face

hammer

polish

mesh

remainder

memo

tone

piano

anatomy

back

wolf

book

servant

football

ticket

way

book

write

pig

throw

frequency

container

catcher

green

factory

game

act

ground

novel

harbor

wine 
APPENDIX (Continued)

63. The suspect saw the police. He burned the pot. The husband roasted the chicken. He burned the pot.

marijuana

pan

64. The bride turned down the money. She preferred the present. The woman reflected on her childhood. She preferred the present.

65. The toddler looked for his pet. He recognized the quack. The victim testified in court. He recognized the quack.

66. The chef prepared the stew. He adjusted the range. The gunner saw the target. He adjusted the range.

67. The groupie loved the song. She kept the record. The boss mailed the invoice. She kept the record.

68. The vacationer made a phone call. He checked the reservation. The trader needed furs. He checked the reservation.

69. The jeweler followed instructions. She modified the ring. The nurse hated the alarm clock. She modified the ring.

70. The gymnast considered the routine. She suggested the roll. The waitress looked at the menu. She suggested the roll.

71. The draftsman made a mistake. He examined the ruler. The healer entered the chamber. He examined the ruler.

72. The hound searched the ground. He lost the scrap. The bully met his match. He lost the scrap.

73. The professor was grading the speech. She heard the sentence. The defendant listened in silence. She heard the sentence.

74. The mechanic repaired the car. He switched the shift. The supervisor was flexible. He switched the shift.

75. The policeman raised the shield. He prevented the shot. The patient hated needles. He prevented the shot.

76. The miner finished the shift. He wanted a shower. The homesteader needed a good crop. He wanted a shower.

77. The delinquent left the scene. He stored the sling. The paramedic stocked the supplies. He stored the sling.

78. The woodpecker penetrated the bark. He removed the slug. The intern opened the wound. He removed the slug.

79. The gravedigger needed help. He offered the spade. The cardsharp wanted to trade. He offered the spade.

80. The driver went to the garage. She needed a spare. The amateur wanted to win. She needed a spare.

81. The mother prepared a sandwich. She smoothed the spread. The maid cleaned the house. She smoothed the spread.

82. The homeowner shoveled the snow. She missed the spring. The upholsterer examined the chair. She missed the spring.

83. The chancellor wanted changes. He dropped the staff. The shepherd was terrified. He dropped the staff.

84. The scientist became famous. He discovered a star. The agent was ecstatic. He discovered a star.

85. The drinker was nervous. He chewed the straw. The hillbilly was loafing. He chewed the straw.

86. The umpire changed his mind. He overruled the strike. The governor recommended the compromise. He overruled the strike.

87. The instructor watched the meet. He analyzed the stroke. The internist was puzzled. He analyzed the stroke.

88. The salesperson rang up the charge. He got the tag. The wrestler needed a break. He got the tag.

89. The buddhist approached the building. He touched the temple. The mortician applied the make-up. He touched the temple. gift

past

duck

doctor

stove

distance

album

organize

hotel

indian

diamond

loud

tumble

bun

measure

king

garbage

fight

grammar

jail

gear

work

gun

arm

bath

rain

shot

cast

snail

bullet

shovel

ace

tire

strike

butter

bed

summer

coil

faculty

pole

sky

movie

sip

hay

out

union

swim

heart

label

touch

church

head 
90. The insomniac laid in bed. He noticed the tick.

clock The vet examined the ear. He noticed the tick.

flea

91. The groom bought the outfit. He included the tie. The sportscaster announced the record. He included the tie.

bow draw

92. The butler got the jelly. He prepared the toast. The bestman rehearsed his lines. He prepared the toast.

bread drink

93. The explorer reached his goal. He made the top. The toymaker carved the wood. He made the top.

climb

spin

94. The operator backed into the wall. He scratched his trunk.

car The animal felt an itch. He scratched his trunk.

elephant

95. The skipper returned to dock. He repaired the vessel.

navy The cardiologist found the problem. He repaired the vessel.

blood

96. The relative grew somber. He pictured the wake.

funeral The skier prepared for the jump. He pictured the wake.

(Manuscript received March 23, 1998; revision accepted for publication February 17, 1999.) 